\title{
Land use and land cover change based on historical space-time model
}

\author{
Qiong Sun, Chi Zhang, Min Liu, and Yongjing Zhang \\ Tourism Institute of Beijing Union University, Beijing, 100101, China \\ Correspondence to: Qiong Sun (sunqiongsqsq@163.com)
}

Received: 29 April 2016 - Published in Solid Earth Discuss.: 16 June 2016

Revised: 17 August 2016 - Accepted: 7 September 2016 - Published: 27 September 2016

\begin{abstract}
Land use and cover change is a leading edge topic in the current research field of global environmental changes and case study of typical areas is an important approach understanding global environmental changes. Taking the Qiantang River (Zhejiang, China) as an example, this study explores automatic classification of land use using remote sensing technology and analyzes historical space-time change by remote sensing monitoring. This study combines spectral angle mapping (SAM) with multi-source information and creates a convenient and efficient high-precision land use computer automatic classification method which meets the application requirements and is suitable for complex landform of the studied area. This work analyzes the histological space-time characteristics of land use and cover change in the Qiantang River basin in 2001, 2007 and 2014, in order to (i) verify the feasibility of studying land use change with remote sensing technology, (ii) accurately understand the change of land use and cover as well as historical space-time evolution trend, (iii) provide a realistic basis for the sustainable development of the Qiantang River basin and (iv) provide a strong information support and new research method for optimizing the Qiantang River land use structure and achieving optimal allocation of land resources and scientific management.
\end{abstract}

\section{Introduction}

Land use refers to all purposeful human land development and use activities; different types of land include agricultural land, forestry land, industrial land, land for transportation and residential land (Ochoa et al., 2016; Muñoz-Rojas et al., 2015). Land use is closely related to land cover, in which the former occurs on the surface of the Earth and the latter is the product of various surface processes including land use (Verburg et al., 2014). Land use and land cover have particular time and space attributes, and their form and feature change in a variety of space and time scales, which generates a series of ecological environmental effects (de Mûelenaere et al., 2014). For instance, El-Kawy et al. (2011) analyzed the categories of land use and cover using satellite images, which provided a theoretical basis for a land management scheme proposal.

With the development of science and technology nowadays, we are able to acquire Earth observation remote sensing data and the understanding of the Earth surface can evolve to a new stage, providing a more powerful and convenient way of acquiring land use and land cover information. Land use and land cover mapping has gained the widest application in the satellite Earth observation field (Gessesse et al., 2015). The methods for studying remote sensing data mainly include the static remote sensing image analysis method and dynamic remote sensing image analysis method.

Static remote sensing image analysis refers to analyzing land cover distribution and changes in different periods, done by processing remote sensing data in some fixed time phase based on field investigation or historical data and then dividing those into different categories.

The dynamic remote sensing image analysis method is the analysis of land cover information in different periods by comparison of remote sensing data in different time phases. Since being developed, it has only covered a few decades; hence, the method is generally applied to study the land cover situation within the period of remote sensing data. Research on land use and land cover is closely associated with the development of mapping and remote sensing technology 
(Gelaw et al., 2015; Zhang et al., 2015). Remote sensing has a great advantage when being applied to research on land use because it can observe the entire picture of an area simultaneously or observe the same area repeatedly. Remote sensing can observe and monitor rapidly changing systems, for instance, land-sea-atmosphere energy exchange, ocean current, atmospheric ozone, as well as system changing in a slow way (Ferreira et al., 2015; Amuti and Luo, 2014). Ahmad et al. (2010) studied soil water content using remote sensing data; Talaulikar et al. (2014) estimated the average cosine value of an underwater light field in the ocean using remote sensing data. By using spectral angle mapping (SAM) and multi-source information innovatively, this study analyzes land use and land cover in the Qiantang River based on a historical space-time model, aiming to provide a powerful information support for the optimization of land use structure in the Qiantang River in Zhejiang and the reasonable allocation of land resource and a new approach for research analysis.

\section{Materials and methods}

\subsection{Research center}

The Qiantang River basin has complex morphology, with $70.4 \%$ mountains and hills, $23.2 \%$ plain and basin and $6.4 \%$ rivers and lakes. The Qiantang River follows through mountainous and hilly land in western Zhejiang. Except the northeastern side, which faces the East China Sea, all sides are surrounded by mountains. It is separated by northeast-trending mountain chains. The basin is high in the southwest and low in the northeast and covered by many hills and few plains. There are mountains around and inside the drainage basin, more than 10 of which are $1500-1800$ m above sea level, such as Liugujian and Qingliang peaks of Baiji Mountain in the trunk region of Xinan River; the average slope of Liugujian and Qingliang Peak was 32 and $25^{\circ}$, respectively (Xu et al., 2013).

The Qiantang River basin is located in a mid-subtropical zone, near ocean, and has frequent monsoon activities. Winter is sunny and cold; spring is dominated by rainy days and the rainy season comes in March and is over by June. July-August is a period with high temperature and drought, in which typhoons and rainstorms appear frequently. Fall usually has fresh air and an invigorating climate (Xu et al., 2014). The annual average temperature of the basin is 16.1$17.7^{\circ} \mathrm{C}$ and the annual rainfall capacity is $1200-2200 \mathrm{~mm}$ (Xia et al., 2014).

Affected by superior hydrothermal conditions and complex topography, plants in the Qiantang River basin are rich in species and types. Zonal vegetation in the basin is midsubtropical evergreen broadleaved forest. A majority of native forest vegetation has been destroyed due to human activity and interference for thousands of years, and some sec- ondary natural evergreen broadleaved forests survive only in local districts that have inconvenient transportation and steep slopes (Xia et al., 2016).

The Qiantang River, $668 \mathrm{~km}$ long from the northern source to estuary, originated from Xiuning County of Anhui province (China) and crosses Anhui, Zhejiang, Jiangxi and Fujian (China). The Qiantang River, which is rich in water (average annual runoff: 43.458 billion $\mathrm{m}^{3}$ ), has functions of electricity generation, flood control, drink water supply, cultivation, irrigation, transportation, sightseeing, etc. Main streams of the Qiantang River basin, $583 \mathrm{~km}$ long, are made up of Qiantang River, Fuchun River, Xin' an River, Lan River, Heng River, Changshan port and Majin rivulet. Main streams above Fuchun power station are mountain rivers with steep slope and rapid water flow; the tidal river reaches are below Fuchun River, with large tidal range in the estuary, which belongs to strong tidal estuary. Main tributary includes Jiangshan Harbor, Lingshan Harbor, Wuxi River, Jinhua River, Shouchang River, Pujiang River and Fengshui River (Su et al., 2011). The map of the Qiantang River basin is shown in Fig. 1 (Shen et al., 2013).

\subsection{Land use and cover automatic classification method based on spectral angle mapping and multi-source information}

\subsubsection{Multi-source information}

\section{Topographic data}

A digital line graph (DLG) $(1: 50000)$ is used in this study as a topographic data source. Relying on ArcGIS analysis function (Xiao et al., 2012), a triangular irregular network can be generated from DLG and then transformed into a digital elevation model. The spatial resolution was $25 \mathrm{~m}$. Then, the gradient and slope aspect information are extracted.

\section{Normalization indexes}

Normalized differential vegetation index, the optimal indicative factor for plant growth condition and spatial distribution density, is lineally associated with plant distribution cover degree, which is the most widely used vegetation index. Water reflection is weakened gradually from visible light to midinfrared band, and water has the strongest absorption in nearinfrared and mid-infrared band and reflects almost nothing. Zhao et al (Zhao and Chen, 2005) compared difference value using the 5th and 6th bands of TM/ETM+. and also established normalized difference bare index (NDBal) in the study of TM/ETM+ bare soil image extraction. 


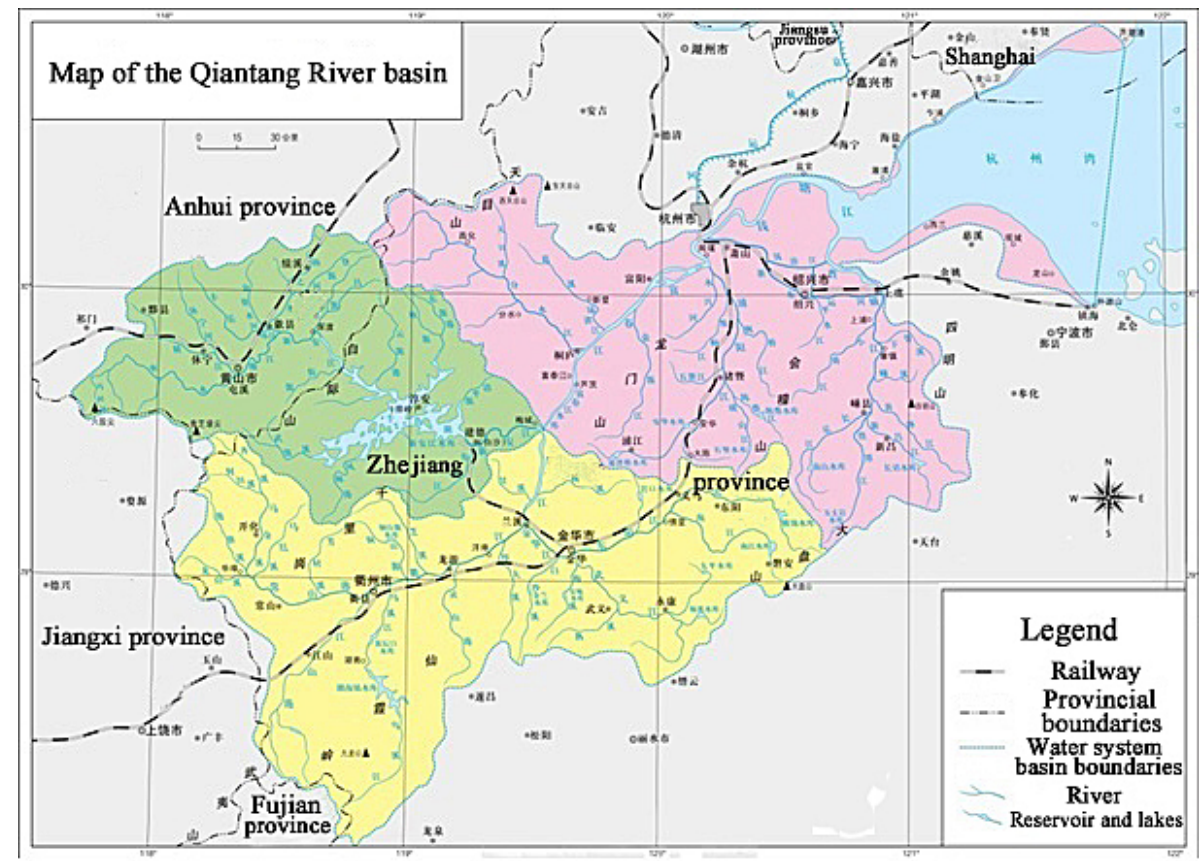

Figure 1. Map of the Qiantang River basin (three colors in the map refer to three trunk regions of the Qiantang River: green is the trunk region of Xinan River, yellow refers to the Lan River region, pink refers to the Fuchun River and Qiantang River regions).

\subsubsection{Classification methods}

\section{Basic principle of spectral angle mapping}

Spectral angle mapping confirms the similarity between a test spectrum and a reference spectrum by calculating their angle (Li et al., 2014). Reference spectrum can be the pixel spectrum extracted from laboratory or field or images. This method assumes that image data have been cut to "apparent reflection"; that is to say, all dark radiation and path radiation deviations have been eliminated. SAM confirms the similarity between test spectrum $t_{i}$ and reference spectrum $r_{i}$ through the following formula:

$\alpha=\cos ^{-1}\left[\frac{\sum_{i=1}^{n_{j}} t_{i} r_{i}}{\left(\sum_{i=1}^{n_{b}} t_{i}^{2}\right)^{\frac{1}{2}}\left(\sum_{i=1}^{n_{b}} \mathrm{r}_{i}^{2}\right)^{\frac{1}{2}}}\right]$.

Herein, $n$ stands for the number of wavebands. The formula seems like solving the angle between two vectors. Spectral reflectance ratio of ground object can be regarded as a vector. If total illumination increases or decreases, the length of the vector will increase or decrease accordingly, but the angle direction remains unchanged.

\section{Classification process}

This study is designed to acquire corresponding topographic data from digital line graph, extract various normalized in- dex information from Thematic Mapper (TM) image and then perform SAM classification and precision evaluation by recombining various multi-source information on TM image. Mixed division of paddy field, dry field and woodland, i.e., whether the consistent vector directions of paddy field, dry yield and woodland in six-dimensional space of original spectral information will induce the low precision of image classification or not, is analyzed according to precision evaluation results in the test area and verification results in the verification area. Finally, conclusions are reached.

\section{Data standardization and training sample selection}

Before SAM classification, normalized index information is standardized between 0 and 255 by Earth Resource Data Analysis System (ERDAS) modeling. Samples are selected for training after the optimal waveband combinations are chosen. Pixel samples (300 dpi) in each area are selected to ensure large differences between spectral vector angles.

\subsection{Brief introduction of land use and cover analysis method}

\subsubsection{Single dynamic degree of land use and cover}

Single dynamic degree of land use and cover refers to the number of some kind of land use and cover change in a certain time in a study area (Sanjuán et al., 2016), and its ex- 
pression formula is

$K=\frac{U_{b}-U_{a}}{U_{a}} \times \frac{1}{T} \times 100 \%$,

where $k$ stands for the dynamic degree of land use and cover in a certain study time, $U_{a}$ stands for the number of land use and cover at the beginning of the study, $U_{b}$ stands for the number of some kind of land use and cover types in the end of the study and $T$ stands for the length of research period. $K$ is considered the annual changing rate of land use and cover type in the study area when $T$ is set as year.

\subsubsection{Dynamic degree of comprehensive land use and cover}

Dynamic degree of comprehensive land use and cover refers to the number of land use change in a certain time in a study area, and its expression formula is

$L C=\left[\frac{\sum_{i=1}^{n} \Delta L U_{i-j}}{2 \sum_{i=1}^{n} L U_{i}}\right] \times \frac{1}{T} \times 100 \%$.

Herein, $L U_{i}$ stands for the area of $i$ th land use and cover type at the beginning of monitoring, $L U_{i-j}$ stands for the absolute value of $i$ land use and cover type transforming into non- $i$ land use and cover type in the monitoring time and $T$ is study phase. $L C$ is the annual changing rate of land use and cover in the study area when $T$ is set as year.

\subsubsection{Comprehensive index of land use and cover}

Comprehensive index of land use and cover in a study area can be expressed as

$L_{j}=100 \times \sum_{i=1}^{n} A_{i} \times C_{i}$

where $L_{j}$ stands for comprehensive index of land use and cover in a study area, $A_{i}$ stands for grading index of level $i$ land use and cover in the area, $C_{i}$ stands for area percentage of level $i$ land use and cover grading in the area and $n$ stands for the number of land use and cover grading.

\subsubsection{Analysis of change degree of land use and cover}

The change of land use and cover in a certain range is the result of changes of various types of land use and cover types, and land use and cover as well as its variation and change rate can quantificationally reveal the overall level and change trend of land use and cover in the range (Yu et al., 2014; Belay et al., 2015). Variation and change rate of land use and cover can be expressed as

$$
\begin{aligned}
& \Delta L_{b-a}=L_{b}-L_{a} \\
& =100 \times\left(\sum_{i=1}^{n} A_{i} \times C_{i b}-\sum_{i=1}^{n} A_{i} \times C_{i a}\right) \\
& R=\frac{\sum_{i=1}^{n}\left(A_{i} \times C_{i b}\right)-\sum_{i=1}^{n}\left(A_{i} \times C_{i a}\right)}{\sum_{i=1}^{n}\left(A_{i} \times C_{i a}\right)} .
\end{aligned}
$$

Herein, $L_{a}$ stands for regional land use and cover comprehensive index at time $a ; L_{b}$ stands for regional land use and cover comprehensive index at time $b ; A_{i}$ stands for level $i$ land use and cover grading index; $C_{i a}$ stands for area percentage of level $i$ land use and cover at time $a$ in an area; $C_{i b}$ stands for area percentage of level $i$ land use and cover at time $b$ in an area; $L_{b-a}$ stands for variable quantity of land use and cover; $R$ stands for change rate of land use and cover.

\subsubsection{Information entropy of land use and cover structure}

"Entropy", a concept of thermodynamics, is considered as a random variable without restriction in information theory (Sato and Suganuma, 2013). The size of entropy can be used to describe average uncertainty degree in probability system and analyze complex land use and cover structure with the help of the concept of entropy in a thorough and quantitative way. Information entropy $(H)$ is defined as follows based on Shannon entropy formula:

$H=-\sum_{i=1}^{n} P_{i} \times=\operatorname{In} P_{i}$,

where information entropy $H$ is used to describe the diversity of land use and cover and $P_{i}$ stands for the proportion of land type $i$. The diversity index is considered as 0 when the area has not been developed, i.e., $H_{\min }=0$; various land types have been stable and meet entropy maximization conditions and the diversity index is maximum when the area has been fully developed, i.e., $H_{\max }=\operatorname{InN}$ ( $n$ stands for land use and cover types).

\subsubsection{Degree of balance and dominance}

Information entropy of land use structure is calculated according to actual number of functions, and the value is usually comparable. Therefore, it is quite necessary to introduce the concept of degree of balance (Zhu et al., 2008). Based on information entropy formula, degree of balance is expressed as

$J=\frac{H}{H_{m}}=-\left[\sum_{i=1}^{n} P_{i} \times \operatorname{In} P_{i}\right]$ and $\operatorname{In} N$
$I=1-J$

where $J$ stands for degree of balance, $E \in[0,1]$, urban land use and cover is in an uneven state when $E$ is equal to 0 , and land use and cover types reach an ideal and balanced situation when $E$ is equal to 1 . I stands for degree of dominance; 
the larger degree of dominance tends to show larger mean value of land use and cover and more balanced land distribution. Hence, compared with information entropy, the index is more intuitive and comparable (Garedew et al., 2009).

\section{Results}

\subsection{Mathematical model analysis methods for land use and cover}

Single dynamics of land use and cover types in the Qiantang River basin from 2001 to 2007, 2007 to 2014 and 2001 to 2014 are shown in Table 1. As a whole, the area of paddy field and dry land is reduced, while forest land, water area and building land increase from 2001 to 2014; building land changes the fastest while forest land changes the slowest.

It can be seen from dynamic degree index of comprehensive land use and cover in Table 1 that from 2001 to 2014 the most changes occurred on dry land, followed by building land and paddy field and lastly forest land. As a whole, the rate and number of building lands change fastest and frequently from 2001 to 2014; dry land changes slowly but the number of dry land changes is greatest; the changing rate and number of paddy fields occupy the third place among all types of land. Therefore, dry land and paddy field belong to sensitive land types in the Qiantang River basin. Water area changes fast, but the number changes little, which is consistent with season-related change in water area. The change speed of forest land change is the slowest and its number change is also the least obvious, which is consistent with the fact that the total area of forest is the largest and the roll-in and roll-out changes are mild. Details are shown in Fig. 2.

\subsection{Analysis of land use and cover degree}

As shown in Table 2, the Qiantang River basin had relatively higher land use and cover, and the land use and cover comprehensive index increased to 233.3582 in 2014 from 232.8926 in 2001. It indicated that land use and cover comprehensive index increased gradually from 2001 to 2014, which suggested that land use and cover in the basin were deepening from 2001 to 2014. The development of social economy is one of the leading factors for land use and cover change and the development of economy predicts the increase of building land.

It can be see from Table 2 that land use and cover in the Qiantang River basin developed and deepened continuously in two stages (2001-2007 and 2007-2014), and land use and cover change rate was larger from 2001 to 2007 than from 2007 to 2014, which showed that the Qiantang River basin developed rapidly from 2001 to 2007.

\subsection{Information entropy and balance degree of land use and cover structure}

Calculation results of land use and cover structural information entropy in 2001, 2007 and 2014 are displayed in Table 3.

It could be seen from Table 3 that land use and cover information entropy in the Qiantang River basin touched the bottom in 2001, suggesting that land use and cover system had a higher degree of order and stronger constitutive property at that time. However, it reached the highest in 2014, which indicated that the land use system increased in degree of disorder and had the minimum degree of order and poor constitutive property. Monotonically increasing land use and cover information entropy showed that land use and cover system in the area developed to a relatively disordered state, and land use and cover structure became more complicated.

As shown in Table 3, degree of balance of land use and cover structure in the Qiantang River basin from 2001 to 2014 increases continuously and degree of dominance is reduced, which indicated that land use and cover structure in the Qiantang River basin is more complicated, the degree of balance is higher and lands are more evenly distributed as economy develops rapidly. To date, land use and cover structure in the Qiantang River basin becomes more harmonious.

\section{Discussion}

Land use and cover data are the basis of investigation on global environmental change and also the key factor in the study of Earth surface activity progress; the exploration involves fields like biochemical circle, plant biomass distribution, climate change and atmospheric circulation. Many research results suggested that recent land use is associated with a large number of industrial and agricultural activities; land use has experienced a great and fast change in the past 50 years, especially in the width and depth. These changes are usually accompanied by the economic increase and population boom as well as the change of production and living (Fuller et al., 2012).

It has been known to all that the change of economy and population is testing the bearing capacity of natural biological environment, and biological damage and resource exhaustion will occur if the bearing capacity is exceeded. Therefore, to relieve biological risks, ensure normal production and standards of living and implement the concept of sustainable development, various countries have invested manpower and material resources for relevant studies; various studies are playing a positive role ( $\mathrm{Li}, 2012$; Hundloe and Mcdonald, 2013).

Currently, research on changes of land use in China concentrates on areas with active human activities and natural motivation, especially developed areas such as Beijing, Yangtze River Delta and Shenzhen and fragile environmental areas under the effects of population increase, econom- 
Table 1. Dynamic degree of land use and cover types in the Qiantang River basin.

\begin{tabular}{l|crr}
\hline Year & Types $\left(\mathrm{km}^{2}\right)$ & $\begin{array}{r}\text { Dynamic degree of } \\
\text { single land use } \\
\text { and cover (\%) }\end{array}$ & $\begin{array}{r}\text { Dynamic degree of } \\
\text { comprehensive land use } \\
\text { and cover (\%) }\end{array}$ \\
\hline \multirow{5}{*}{$2001-2007$} & -1.42 & 8.01 \\
& Paddy field & -2.31 & 11.13 \\
& Dry land & 0.18 & 0.39 \\
& Forest land & 3.05 & 1.87 \\
& Water area & 4.71 & 7.52 \\
& Building land & -1.23 & 8.57 \\
& Paddy field & -2.96 & 12.06 \\
& Dry land & 0.29 & 0.49 \\
& Forest land & 4.53 & 1.61 \\
& Water area & 6.12 & 5.96 \\
\hline Building land & Paddy field & -1.29 & 4.23 \\
& Dry land & -2.56 & 7.98 \\
& Forest land & 0.25 & 0.23 \\
& Water area & 3.72 & 0.89 \\
& Building land & 5.93 & 4.82 \\
\hline
\end{tabular}

Table 2. Land use and cover comprehensive index, variation and change rate in the Qiantang River basin.

\begin{tabular}{ccc|ccc|ccc}
\hline $\begin{array}{c}\text { Comprehensive index of land use } \\
\text { and cover }\end{array}$ & \multicolumn{3}{c|}{$\begin{array}{c}\text { Land use and cover } \\
\text { variation quantity }\end{array}$} & \multicolumn{3}{c}{$\begin{array}{c}\text { Land use and cover } \\
\text { degree change ratio (\%) }\end{array}$} \\
\hline 2001 & 2007 & 2014 & $2001-2007$ & $2007-2014$ & $2001-2014$ & $2001-2007$ & $2007-2014$ & $2001-2014$ \\
\hline 232.8926 & 233.0125 & 233.3582 & 0.1562 & 0.1249 & 0.2811 & 0.0602 & 0.0816 & 0.1418 \\
\hline
\end{tabular}

Table 3. Land use and cover structure, information entropy and degree of balance and dominance in the Qiantang River basin in 2001, 2007 and 2014.

\begin{tabular}{lccc}
\hline & 2001 & 2007 & 2014 \\
\hline Paddy field \% & 12.96 & 11.56 & 10.43 \\
Dry land \% & 11.86 & 10.12 & 9.63 \\
Forest land \% & 67.93 & 68.45 & 69.15 \\
Water area \% & 3.85 & 4.06 & 4.37 \\
Building land & 4.09 & 5.02 & 5.98 \\
Number of functions & 5 & 5 & 5 \\
Information entropy & 1.0203 & 1.0296 & 1.0312 \\
Degree of balance & 0.6351 & 0.6332 & 0.6362 \\
Degree of dominance & 0.3639 & 0.3623 & 0.3601 \\
\hline
\end{tabular}

ical development and resource consumption such as northeast China region and Yulin region in a transitional zone between arid and semiarid regions. Zhejiang Qiantang River researched in this study belongs to the first category. Differing from such popular research areas as Guangzhou and Shanghai (Fan et al., 2007; Yin et al., 2011), Qiantang River has been seldom studied in the past. The Qiantang River basin, located in the west of Zhejiang province, is one of Zhejiang top eight river systems and also the largest river in Zhejiang province. Moreover, the basin has rich agricultural resources and a long development history. It is an important area for comprehensive development of agriculture, forest, grazing, subsidiary business, and fishing and cultivation of Zhejiang civilization. Changes of land use and cover in the basin are obvious in the past decades. Results of this study can guide the transformation of local land type and help people to utilize land resource better on the premise of environmental protection.

Research methods for land use and cover include remote sensing data methods, model research methods and field observation methods (Iqbal and Khan, 2014; Trabaquini et al., 2015). This study made an automatic classification of land use and covers in the Qiantang River and made a time-space analysis on land use and cover of the Qiantang River from 2001 to 2014. Considering the complex terrain, intensive land use and frequent changes of land use, we found a simple, efficient and highly precise automatic classification method based on multi-source data in combination with SAM. Compared to maps obtained using nonautomated methods, maps obtained using multi-source information combined with SAM can save cost and time spent on screening and calculation and have improved accuracy. 

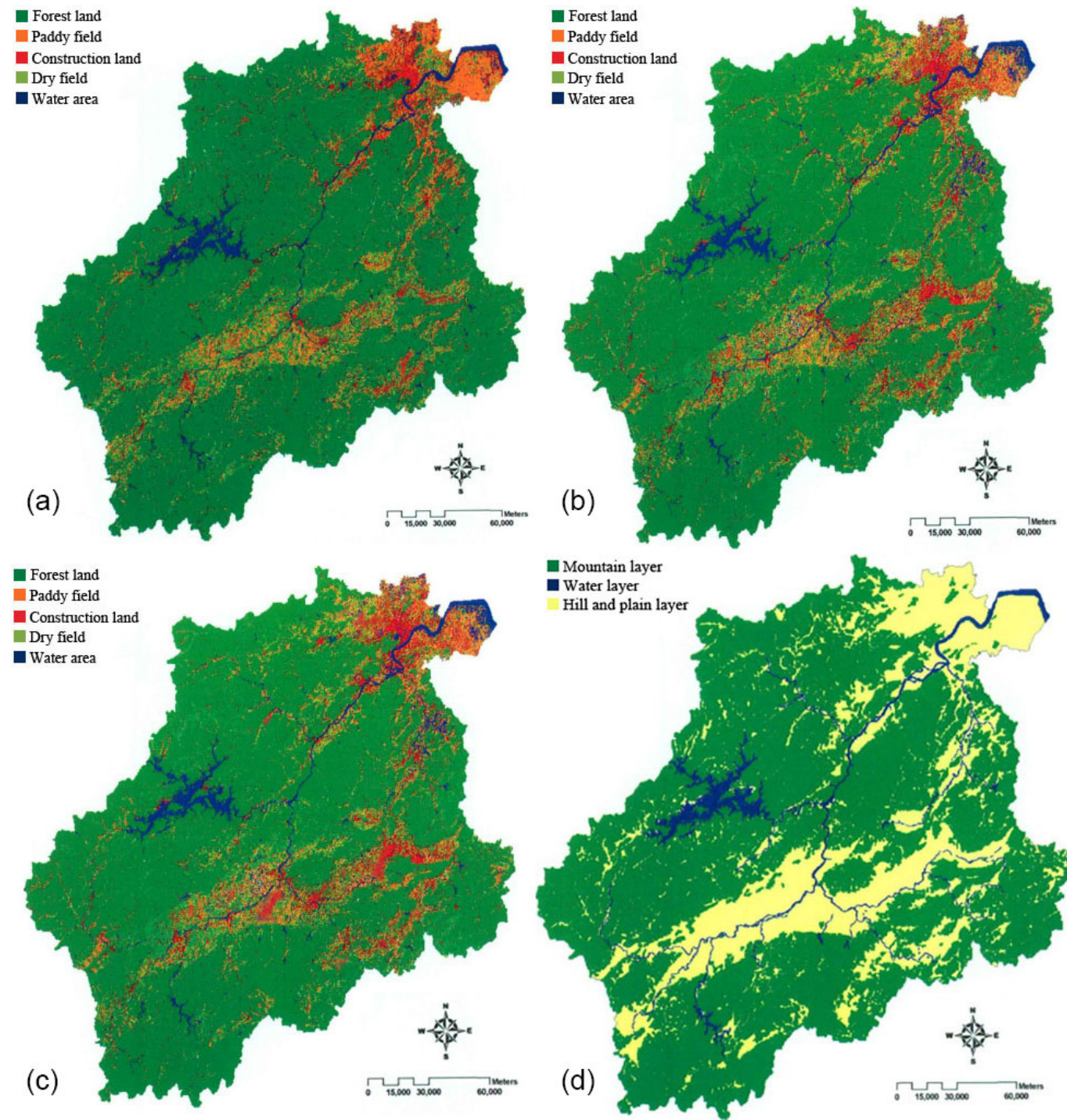

Figure 2. Map of the Qiantang River basin and spectral angle mapping based automatic classification of land use and cover of the Qiantang River basin in year 2001, 2007 and 2014.

Based on the maps for classification of land use and cover of the Qiantang River in 2001, 2007 and 2014, we made a mathematical model analysis of land use and cover in the Qiantang River and figured out the rules of land use and cover in the Qiantang River. Compared to studying the Qiantang River basin using remote sensing and GIS technology (Wu and Zhang, 2012), the method adopted by this study is more specific and efficient. The automatic classification method integrating multi-source data and SAM is applicable to research concerning areas with complex terrain and is expected to provide an orientation for similar researches.

\section{Conclusion}

This study analyzed the land use and cover in the Qiantang River basin from 2001 to 2014, aiming to achieve two objec- tive: (i) to verify the feasibility of studying land use changes using remote sensing technology and (ii) to accurately understand the land use and cover situation of the Qiantang River basin and historical time-space evolution trend. The level of land use and cover in the Qiantang River basin is high and being deepened. Land use and cover information entropy in the Qiantang River basin touches the bottom in 2001, suggesting that land use and cover system has a higher degree of order and stronger constitutive property. However, it reaches the highest in 2014, which indicates that land use system increases in degree of disorder and has the minimum degree of order and poor constitutive property. The above research results provide a realistic basis for the sustainable development of the Qiantang River basin. (iii) Degrees of balance of land use and cover structure in the Qiantang River 
basin from 2001 to 2014 increases continuously and degree of dominance is reduced. It, to some extent, provides information support and analysis direction for the optimization of the land use structure of the Qiantang River basin and the optimal allocation and scientific management of land resource.

Acknowledgements. This study was supported by a grant from the Science and Technology Project of Beijing Municipal Education Commission (to Sun Qiong) (no. KM201511417009).

Edited by: P. Pereira

Reviewed by: two anonymous referees

\section{References}

Ahmad, S., Kalra, A., and Stephen, H.: Estimating soil moisture using remote sensing data: A machine learning approach, Adv. Water Resour., 33, 69-80, 2010.

Amuti, T. and Luo, G.: Analysis of land cover change and its driving forces in a desert oasis landscape of Xinjiang, northwest China, Solid Earth, 5, 1071-1085, doi:10.5194/se-5-1071-2014, 2014.

Belay, K. T., Van Rompaey, A., Poesen, J., Van Bruyssel, S., Deckers, J., and Amare, K.: Spatial analysis of land cover changes in Eastern Tigray (Ethiopia) from 1965 to 2007: are there signs of a forest transition?, Land Degrad. Developm., 26, 680-689, doi:10.1002/ldr.2275, 2015.

de Mûelenaere, S., Frankl, A., Haile, M., Poesen, J., Deckers, J., Munro, N., Veraverbeke, S., and Nyssen, J.: Historical landscape photographs for calibration of Landsat land use/cover in the Northern Ethiopian highlands, Land Degrad. Dev., 25, 319335, doi:10.1002/ldr.2142, 2014.

El-Kawy, O. R. A., Rød, J. K., Ismail, H. A., and Suliman, A. S.: Land use and land cover change detection in the western Nile delta of Egypt using remote sensing data, Appl. Geogr., 31, 483494, 2011.

Fan, F. L., Weng, Q. H., and Wang, Y. P.: Land Use and Land Cover Change in Guangzhou, China, from 1998 to 2003, Based on Landsat TM/ETM+ Imagery, Sensors, 7, 1323-1342, 2007.

Ferreira, C. S. S., Walsh, R. P. D., Steenhuis, T. S., Shakesby, R. A., Nunes, J. P. N., Coelho, COA., and Ferreira, A. J. D.: Spatiotemporal variability of hydrologic soil properties and the implications for overland flow and land management in a peri-urban Mediterranean catchment, J. Hydrol., 525, 249-263, doi:10.1016/j.jhydrol.2015.03.039, 2015.

Fuller, D. O., Parenti, M., Gad, A., and Beier, J.: Land cover in Upper Egypt assessed using regional and global land cover products derived from MODIS imagery, Remote Sens. Lett., 3, 171-180, 2012.

Garedew, E., Sandewall, M., Söderberg, U., and Campbell, B. M.: Land-use and land-cover dynamics in the central rift valley of Ethiopia, Environ. Manage., 44, 683-694, 2009.

Gelaw, A. M., Singh, B. R., and Lal, R.: Organic Carbon and Nitrogen Associated with Soil Aggregates and Particle Sizes Under Different Land Uses in Tigray, Northern Ethiopia, Land Degrad. Dev., 26, 690-700, doi:10.1002/ldr.2261, 2015.

Gessesse, B., Bewket, W., and Bräuning, A.: Model-based characterization and monitoring of runoff and soil erosion in response to land use/land cover changes in the Modjo Watershed, Ethiopia, Land Degrad. Dev., 26, 711-724, doi:10.1002/ldr.2276, 2015.

Hundloe, T. and Mcdonald, G.: Ecologically Sustainable Development and the Better Cities Program, Australas. J. Environ, 4, 88111, 2013.

Iqbal, M. F. and Khan, I. A.: Spatiotemporal Land Use Land Cover change analysis and erosion risk mapping of Azad Jammu and Kashmir, Pakistan, Egypt, J. Remote Sens. Space Sci., 17, 209229, 2014.

Li, H., Lee, W. S., Wang, K., Ehsani, R., and Yang, C. H.: "Extended spectral angle mapping (ESAM)" for citrus greening disease detection using airborne hyperspectral imaging, Precis. Agric., 15, 162-183, 2014.

Li, Z.: On the Establishment of Ecological Circular Economy under the Guidance of Sustainable Development Concept, Adv. Mater. Res., 524-527, 3647-3650, 2012.

Muñoz-Rojas, M., Jordán, A., Zavala, L. M., De la Rosa D, AbdElmabod, S. K., and Anaya-Romero, M.: Impact of land use and land cover changes on organic carbon stocks in Mediterranean soils, Land Degrad. Dev., 26, 168-179, doi:10.1002/ldr.2194, 2015.

Ochoa, P. A., Fries, A., Mejía, D., Burneo, J. I., Ruíz-Sinoga, J. D., and Cerdà, A.: Effects of climate, land cover and topography on soil erosion risk in a semiarid basin of the Andes, Catena, 140, 31-42, doi:10.1016/j.catena.2016.01.011, 2016.

Sanjuán, Y., Gómez-Villar, A., Nadal-Romero, E., ÁlvarezMartínez, J., Arnáez, J., Serrano-Muela, M. P., Rubiales, J. M., Gon-zález-Sampériz, P., and García-Ruiz, J. M.: Linking land cover changes in the sub-slpine and montane belts to changes in a torrential river, Land Degrad. Dev., 27, 179-189, doi:10.1002/ldr.2294, 2016.

Sato, T. and Suganuma, M.: Consideration of expression method of the entropy concept: correlation between the thermodynamic entropy obtained from the molecule movement animation and the psychological quantity from language expression, Trans. Jpn. Soc. Kansei Eng., 12, 303-309, 2013.

Shen, X., Xu, H. L., Han, Y. C., and Tao, C. J.: Study on Water Quality Control of Qiantang River Watershed, Environ. Sci. Manage., 38, 68-71, 2013.

Su, S., Zhi, J., Lou, L., Huang, F., Chen, X., and Wu, J. P.: Spatio-temporal patterns and source apportionment of pollution in Qiantang River (China) using neural-based modeling and multivariate statistical techniques, Phys. Chem. Earth Pt. A/B/C, 36, 379-386, 2011.

Talaulikar, M., Suresh, T., Desa, E., and Inamdar, A.: An empirical algorithm to estimate spectral average cosine of underwater light field from remote sensing data in coastal oceanic waters, Limnol. Oceanogr.-Meth., 12, 74-85, 2014.

Trabaquini, K., Formaggio, A. R., and Galvã,o L. S.: Changes in physical properties of soils with land use time in the Brazilian savanna environment, Land Degrad. Dev., 26, 397-408, doi:10.1002/ldr.2222, 2015.

Verburg, P. H., Schot, P. P., Dijst, M. J., and Veldkamp, A.: Land use change modeling: current practice and research priorities, Geojournal, 61, 309-324, 2014.

Wu, K. Y. and Zhang, H.: Land use dynamics, built-up land expansion patterns, and driving forces analysis of the fast-growing Hangzhou metropolitan area, eastern China (1978-2008), Appl. Geogr., 34, 137-145, 2012. 
Xia, F., Liu, X. M., Xu, J., Wang, Z. G., Huang, J. F., and Brookes, P.: Trends in the daily and extreme temperatures in the Qiantang River basin, China, Int. J. Climatol., 35, 6553-6565, 2014.

Xia, F., Liu, X. M., Xu, J. M., Yu, L. J., and Shi, Z.: Precipitation change between 1960 and 2006 in the Qiantang River basin, eastern China, Clim. Res., 67, 257-269, 2016.

Xiao, J. F., Wang, X. D., and Yao, Y.: Underground pipe network spatial analysis in large plant with ArcGIS, J. Comput. Appl., 32, 2675-2678, 2012.

Xu, Y. P., Zhang, X., Ran, Q., and Tian, Y.: Impact of climate change on hydrology of upper reaches of Qiantang River Basin, East China, J. Hydrol., 51-60, 483, 2013.

Xu, Y. P., Ma, C., Pan, S. L., Zhu, Q., and Ran, Q. H.: Evaluation of a multi-site weather generator in simulating precipitation in the Qiantang River Basin, East China, J. Zhejiang Univ.-Sci. A, 15, 219-230, 2014.

Yin, J., Yin, Z. E., Zhong, H. D., and Wu, J. P.: Monitoring urban expansion and land use/land cover changes of Shanghai metropolitan area during the transitional economy (1979-2009) in China, Environ. Monit. Assess., 177, 609-621, 2011.
Yu, B., Stott, P., Di, X. Y., and Yu, H. X.: Assessment of land cover changes and their effect on soil organic carbon and soil total nitrogen in Daqing prefecture, China, Land Degrad. Dev., 25, 520531, doi:10.1002/ldr.2169, 2014.

Zhang, F., Tiyip, T., Feng, Z. D., Kung, H. T., Johnson, V. C., Ding, J. L., Tashpolat, N., Sawut, M., and Cui, D. W.: Spatio-temporal patterns of land use/cover changes over the past 20 years in the middle reaches of the tarim river, Xinjiang, China, Land Degrad. Dev., 26, 284-299, doi:10.1002/ldr.2206, 2015.

Zhao, H. and Chen, X.: Use of normalized difference bareness index in quickly mapping bare areas from TM/ETM+, Geosci. Remote Sens. Sympos., 3, 1666-1668, 2005.

Zhu, W., Wang, D. H., and Zhou, X. G.: The research of optimizing DEM resolution based on information entropy, Remote Sens. Informat., 18, 79-82, 2008. 